\title{
Antecedents of Engagement in Community-Based Crowdsourcing
}

\author{
Triparna de Vreede \\ University of South Florida \\ tdevreede@usf.edu
}

\author{
Gert-Jan de Vreede \\ University of South Florida \\ gdevreede@usf.edu
}

\author{
Roni Reiter-Palmon \\ University of Nebraska at Omaha \\ rreiter-palmon@unomaha.edu
}

\begin{abstract}
Organizations are increasingly pursuing crowdsourcing initiatives to gain an understanding of community issues. A critical success factor for community crowdsourcing is to attract online volunteer crowdsourcing users and engage their interest besides extrinsic motivators like monetary rewards. Our study examines determinants of participant engagement in online crowdsourcing communities, specifically motivation to contribute, personal interest in topic, and goal clarity. The results provide strong support for (a) the positive relationship between an individual's motivation to contribute towards a task and their engagement towards that task; (b) the positive relationship of a person's interest in the topic and their motivation to contribute; and (c) the partial mediating role of motivation to contribute. No significant effect was found for the hypothesis that clearer goals resulted in higher engagement since they led to a higher motivation to contribute when there was an inherent personal interest towards the topic.
\end{abstract}

\section{Introduction}

The past decade has welcomed many fascinating and life altering technologies. The mobile Internet revolution has transformed social networks and connected people like never before. Social media allow anyone with Internet access to effectively connect, communicate, and collaborate with the rest of the world. These developments are changing how organizations liaise with internal and external stakeholders. However, with new collaboration technologies being constantly introduced into the market, the competition is also rising. A critical factor that determines the survival of such products is user engagement $[10,43,71]$. Technologies that fail to attract and retain users' interest eventually die out. Thus, a critical challenge for developers and researchers is: How can we ensure that collaboration technology users remain highly engaged while using it? We focus on one technology where an understanding of engagement has become critical in recent years: crowdsourcing.

Crowdsourcing entails taking a task that is traditionally performed by an employee or a group of employees and outsourcing it to a large, undefined group of people, through an open call for contributions [35]. Crowdsourcing enables the effective utilization of the brainpower and ideas of millions of people for a relatively small price [28]. While studies report impressive results (e.g. [7,28]), crowdsourcing initiatives also face their own share of challenges.

One key challenge for crowdsourcing organizations is attracting and sustaining engaged workers. For example, Brabham [11] emphasizes that crowdsourcing can create higher levels of engagement between people and government and argues that sustained user engagement plays an important role in the success or failure of crowdsourcing initiatives. Other researchers note that systematically engaging a crowd is one of the major struggles for organizations utilizing crowdsourcing [24] and that poor or lacking engagement results in a sub-par intellectual effort obtained from the crowd [28]. Moreover, participant engagement may be one of the main factors that differentiate successful crowdsourcing efforts from unsuccessful ones [42]. In the future there are likely to be more requests for crowd contributions than there will be participants to make them. It can be expected that participants will prefer to keep using crowdsourcing sites that are more engaging to them.

While researchers highlight the importance of and challenges associated with engagement in crowdsourcing, there is a dearth of empirical research on crowdsourcing engagement. Therefore, the goal of this paper to empirically evaluate a model of crowdsourcing engagement that proposes three antecedents: Motivation to contribution, personal interest in topic, and goal clarity. We focus our investigation on a particular form of crowdsourcing called community-based crowdsourcing, where online crowds collaborate to create a synthesis of ideas and solutions that could be useful to the problem owner (e.g. the city council or other governing body).

The remainder of this paper is structured as follows: The next section describes community crowdsourcing and engagement. Next, we present our research model and hypotheses and describe the details of our research method. We conclude the paper with a presentation of our results and a discussion of our key findings, their implications, the limitations of our study, and future research directions.

\section{Background}

\subsection{Community Crowdsourcing}

In community crowdsourcing a problem owner solicits online crowds (usually within a specific geographical 
community) to collaborate with each other to address a particular community-relevant issue [61]. The crowd works together as they attempt to find a solution or formulate recommendations [61]. An example of a community crowdsourcing service provider is mySidewalk (http://app.mysidewalk.com/; formerly MindMixer). Universities, city halls, and civil offices have used applications like mySidewalk to enlist the help of online citizens to solve various communal issues. An example of a problem posed on mySidewalk is "What's your big idea for fostering entrepreneurship in Greenville?" Online citizens (or netizens) contribute towards a solution to the issues raised by the problem owner either by generating their own ideas and solutions, by commenting on other people's ideas, or by voting and prioritizing to reduce a large set of solutions/ideas to a more manageable set that they feel deserve more attention from the problem owner.

Unlike reward-based forms of crowdsourcing (e.g. labor markets like Amazon's Mechanical Turk a.k.a. MTurk), community crowdsourcing typically offers no direct monetary benefit. Also, it encourages participants to go beyond making a one-time contribution in response to a problem. Participants in community crowdsourcing have the opportunity to be continuously involved over the lifetime of the project by returning to the ongoing discussion at different points in time. This involvement may be passive where users are merely observing the ideas and discussion among other participants, or it may be more active in the form of contribution of new ideas, feedback, and opinions.

The lack of monetary rewards in this form of crowdsourcing makes it an interesting opportunity to study engagement. The purpose of community-based crowdsourcing is to enable the members of the community to contribute towards the betterment of their society. Motivation to contribute in communitybased crowdsourcing stems from more intrinsic sources; Citizens are motivated by the idea that their contributions will enable the development of their community. This dependence on intrinsic motivation places a greater responsibility on the organizers to ensure that the characteristics of the crowdsourcing site and the questions asked are conducive to sustained user involvement and participation.

\subsection{Engagement}

In general, engagement is "a state of being busy, occupied, or deeply involved in some activity" [53]. Crowd engagement can be considered an amalgamation of the degree and quality of participation by each individual in the crowd in problem solving projects [5]. Researchers from various disciplines agree that engagement is a multidimensional construct consisting of behavioral, cognitive, and emotional components
$[27,37,82]$. Accordingly, it is generally agreed upon that it is more appropriate to simultaneously evaluate all constructs that form engagement rather than focusing on one aspect at a time [15,27,37].

The behavioral component of engagement has been highlighted several times in the literature. For example, in the context of online consumer behavior, engagement is a customer's behavioral manifestation of motivation to buy a product [77] or the willingness to continue to apply effort to experience a website completely and perform customer activities like browsing, purchasing, and leaving reviews [54]. In the workplace, engagement is the degree to which the employees exhibit activities that "go beyond" the expected behaviors [33]. Student engagement refers to the "efforts" of the students towards "educationally purposeful" activities [36]. Finally, civic engagement is often defined by the "level of participation" of the volunteers [9]. For community crowdsourcing, we argue that the behavioral component manifests itself as the willingness to participate online in the community problem solving activities.

The cognitive component relates to the level of intellectual effort that participants expend to make contributions. Research on learning and memory suggests that use of different strategies requires varying levels of cognitive effort, e.g. [2,16]. Shallow processing strategies like mechanically reading information, result in a less elaborate memory representation and limited retrieval and generalizability of information [81]. Consequently, it can be contended that contributors who employ shallow processing strategies will be less engaged in the information exchange process. On the other hand, using meaningful or elaborate information processing strategies results in richer and more coherent ideas, as users are better able to integrate all available information with their existing knowledge [81]. Research has repeatedly shown that material appears more engaging to the reader when they utilize elaborate processing strategies, e.g. [31,40, 55]. Therefore, we argue that crowdsourcing participants' level of engagement is related to the elaborateness of their information processing strategies.

Finally, the emotional component of engagement is also important in the crowdsourcing context. Both education and workplace research demonstrate that positive emotions play a major role in sustaining engagement towards activities. For example, students who were actively engaged in learning showed positive emotions like enthusiasm, optimism, curiosity, and interest [72]. Similar observations have been made in the workplace with engaged employees displaying positive emotions like satisfaction, enthusiasm, positive energy, and alertness to the surroundings [51]. Applying these observations to crowdsourcing, we 
argue that crowdsourcing users who are actively engaged in the information exchange process will display positive affectivity. In other words, engaged contributors will identify with the activity and will experience fulfillment for being involved in it.

Consequently, we define engagement of individuals in community-based crowdsourcing as a three-part construct: A person who is engaged in an crowdsourcing activity displays a willingness to perform the activity, offers cognitive effort towards it, and experiences positive affect after performing it.

\section{Research Model and Hypotheses}

The first antecedent to engagement is motivation to contribute. Motivation plays a positive role in the sustainment of an individual's involvement in an activity $[12,47]$. Stated differently, it may prove to be difficult to elicit engagement from individuals if they had no motivation to contribute in the first place. To be motivated essentially means "to be moved" to do something [65]. Pinder [58] defines motivations as " $a$ set of energetic forces that originates both within as well as beyond an individual's being, to initiate workrelated behavior, and to determine its form, direction, intensity, and duration" (p.11). Pinder thus associates motivation with an energizing force to commit an act. His definition highlights the existence of some factors that channel and sustain the behavior over time. When individuals are motivated, they experience an explicit intention to contribute towards the task. Finally, Pinder's definition also makes it explicit that the intention to act persists over time with sufficient intensity till a desired behavioral expression is obtained.

According to self-determination theory [20], there are two main aspects of motivation - intrinsic motivation and extrinsic motivation. Individuals experience an intrinsic motivation to do something only when they find the activity inherently enjoyable, interesting, or attractive. Extrinsic motivation, on the other hand, means that the individuals are performing the activity because they expect it to lead to a distinct external benefit like rewards or recognition.

The concept of extrinsic monetary rewards as positive reinforcement is greeted with skepticism by some crowdsourcing researchers who argue that such rewards will eventually fail to sustain desired behavior $[64,83]$. This assertion is in line with motivation research, which suggests that extrinsic rewards may actually have the opposite effect and act as "negative reinforcers" to motivation, e.g. $[22,44]$. These findings have been supported in crowdsourcing as well where economic motivators were found to be less effective than psychosocial motivators in eliciting repeat contributions [12] and did not improve the quality of work and extent of engagement in the work [64]. Since quality of work is of most consequence in communitybased crowdsourcing initiatives, monetary compensation is rarely, if ever, utilized to attract participation.

Several studies illustrate the close relationship between intrinsic motivation and engagement in a variety of disciplines. For instance, students who exhibit higher levels of intrinsic motivation perform better at schoolwork and experience less resentment towards it [66]. Intrinsically motivated learners also demonstrate significantly greater levels of cognitive engagement compared to learners who are not motivated [52]. Workplace research also demonstrates a positive relationship between intrinsic motivation and engagement. For example, Gillet et al. found that engagement among police officers was strongly related to their intrinsic motivation [29]. These results were replicated in a laboratory study that showed that workplace conditions which were conducive to the psychological well being of employees positively influenced their intrinsic motivation to work which in turn was positively related to their work engagement [3].

The few studies on the relationship between intrinsic motivation and engagement in crowdsourcing indicate that intrinsic motivation is crucial in inducing participation. Zheng et al. [83] demonstrate that in crowdsourcing contests intrinsic motivation plays a more pivotal role in inducing participation than extrinsic motivation. Examining the effects of intrinsic motivation on the creation of high quality products in MTurk, Rogstadius et al. [64] found that higher pay did not result in increased output accuracy. However, higher levels of intrinsic motivation resulted in a significant increase in output accuracy. Another study on MTurk found that while extrinsic motivation had a strong effect on the time spent on MTurk, it was intrinsic motivation (specifically "fun" and "enjoyment") that had a strong positive influence on the engagement of the crowdsourcing workers [41]. Other intrinsic factors that influenced engagement included the opportunity for skill variety and task autonomy.

A complimentary perspective towards motivation in the context of engagement is provided by the theory of planned behavior (TPB) [1]. TPB suggests that one of the important determinants of a person's behavior is his or her decision on how to behave, i.e. behavioral intention. Thus, TPB looks at motivation in terms of intention - a person's motivation in the context of his or her conscious decision to exercise effort to perform a certain activity. Based on this theory, whether or not an individual will be engaged in an activity will depend on the direction (should I vs. should I not) and strength (to what degree do I want to or not want to) of their behavioral intention.

Technology researchers have used TPB to investigate people's intention to start using a 
technology see e.g. the Technology Transition Model (TTM) and the Technology Acceptance Model (TAM) that both stress the importance of 'intention to use' in the sustained engagement with a new technology $[13,17]$. These models posit that the actual degree of use is directly influenced by 'behavioral intention', which measures the strength of one's intentions to perform that specific behavior [13]. As TPB assumes that an individual's behavior is under his or her control, this theory can be best utilized for volitional behaviors like intention to contribute to a communitybased crowdsourcing website. For our study the construct motivation to contribute is a combination of intrinsic motivation as well as intention to contribute as adapted from TPB. Thus, we hypothesize:

H1. Crowdsourcing users who are more motivated to contribute will display greater engagement than users who are less motivated to contribute.

Engagement in crowdsourcing is also affected by personal interest in the topic. Users who are not personally interested in the topic are less likely to be motivated to make meaningful contributions, irrespective of the absolute importance of the issue. Lohman [50] found that personal interest was predictive of online engagement. His survey study examined the factors influencing the engagement of public school teachers in informal online learning activities. Teachers who showed interest in the profession or commitment to learning the given issue were more likely to be more engaged in the learning activities. Further, in online communities personal interest was a critical element for online citizens to form a "semiosphere" - a social space where interactions are allowed and encouraged [74]. It is in these semiospheres that people displayed most engagement behaviors.

There are two types of interest: topical interest and situational interest [26]. Topical interest refers to an individual's lasting preference for specific topics, tasks, or contexts [75]. It develops over a period of time (e.g., developing a hobby), is content based, and is inherently stable [68]. Studies show that topical interest has a stronger effect on the application and transfer of knowledge and on engagement towards the topic rather than on simple activities like recognition of facts [69]. Benton et al. [8] found that individuals who were interested in the topic wrote better quality essays, both in terms of relevant information included and the thematic complexity of the sentences. Tobias and Everson [76] discovered that interest in the topic was positively related to metacognition (the ability to understand and monitor one's cognitive processes).

Situational interest is "temporary interest that arises spontaneously due to environmental factors such as task instructions or an engaging text" [84]. This type of interest is an emotional state that is transient in nature, short-lived, context dependent, and environmentally activated [70] and is mostly based on topic novelty, reader curiosity, and the salience of the informational content [79]. Studies show that cognitive engagement and situational interest may be affected by text novelty [79], imagery [30], vividness [38], and text organization [80]. Wade et al. [80] further found that referential coherence created through connective phrases and the salience of the information presented had a significant effect on situational interest as well as on cognitive engagement. One explanation for these findings is that situational interest allows individuals to experience a sense of choice in what is being presented to them $[19,56,84]$. This choice increases intrinsic motivation as it satisfies the need for autonomy, which in turn leads to increased engagement [21]. In our study, we focus on situational interest as it aligns with the type of issues that community crowdsourcing addresses: they are typically contextually relevant rather than focusing on people's lasting and stable interests.

While research strongly suggests a direct relationship between personal interest and engagement, some studies suggest that the relationship between personal interest and engagement is mediated by other factors $[4,63,34]$. Especially intrinsic motivation has been frequently mentioned in the literature as being related to personal interest [62]. Assor et al. [4] found that when students found the topic interesting, they were more intrinsically motivated which, in turn, resulted in higher engagement. In fact, some researchers suggest that the presence of interest implies the presence of intrinsic motivation to perform the activity: "intrinsically motivated behaviors are those the person undertakes out of interest" [21, p.241]. In conclusion, it appears that personal interest has a strong influence on engagement, partly mediated by user motivation to contribute. We hypothesize:

H2. Crowdsourcing users who have a personal interest in the topic will be more motivated to contribute than users who are not interested in the topic.

H3. Motivation to contribute will partially mediate the relationship between personal interest in the topic and the level of engagement in the topic.

Goal clarity refers to the degree to which the objectives of a task are clearly stated and unambiguous [67]. In crowdsourcing, goal clarity refers to the extent to which the instructions make it clear what users are expected to do. Research consistently found that goal setting improves motivation [48,49]. However, mere goal setting is not enough; goals also need to be clearly understood by individuals for them to be truly motivated to perform [6]. For example, Sonnentag and Volmer [73] found that team goal clarity enhanced 
individual performance in teams because it allowed the team members to be aware of their responsibilities, which, in turn, motivated them to do their best. Online shopping research revealed that on shopping websites that clearly explained what how shopper had to perform their activities, users exhibited more exploratory behavior, sense of control, revisit intentions, purchase intention, and positive attitude towards these websites [14,18,32]. Zheng et al. [83] demonstrated that explicitly specified tasks enable crowdsourcing users to be intrinsically motivated to participate in a co-creation process.

For community crowdsourcing, the relationship between goal clarity and motivation to contribute is not completely direct and clear cut. We argue that the effect of goal clarity on motivation to contribute is only present when users are actually interested in the topic itself. Since community crowdsourcing typically offers few external rewards to the contributors, the likelihood of citizens spending their time perusing crowdsourcing topics that are not personally interesting is low. A key motivator in community crowdsourcing is to make a meaningful difference in the community. Therefore, it stands to reason that only individuals who perceive a personal interest in the topic will share their ideas and opinions. Consequently, we argue that the effect of goal clarity on motivation to contribute is only observable on the members who are personally interested in the topic. Accordingly, we hypothesize that goal clarity moderates the relationship between personal interest and motivation:

H4. There will be an interaction between goal clarity and personal interest on motivation. That is, crowdsourcing users who are personally interested in the topic will be more motivated to contribute than those who are not interested in the topic and this effect will be stronger when the goals of the task are clear.

\section{Method}

\subsection{Pilot studies}

Two pilot studies were conducted. The purpose of pilot 1 was to identify four topics that were of varied interest to different participants. For this pilot, 248 US-based participants were recruited through MTurk to indicate their interest in 31 different topics. Each topic consisted of a title and a more detailed description. Participants responded to an adaptation of the personal interest instrument from [69]. Participants indicated how they felt while reading the topic and its description (feeling related scale). Participants were also asked to rate the value of the topic to them personally (value related scale). A participant score of topic interest was calculated by adding the feeling related and the value related scales (Cronbach $\alpha .94$ ).
The topic for the main study had to elicit varying degrees of personal interest in the participants, i.e. a high standard deviation in personal interest scores. However, the standard deviation should originate from a varied range of scores and not from outliers. In the end, four topics (Should People Become Vegetarian; Should the US Return to a Gold Standard; Are Cell Phones Safe; Should Students Have to Wear School Uniforms) were selected.

The purpose of pilot 2 was to develop and test the goal clarity manipulation. In this pilot, participants evaluated either a clear goal or unclear goal version of each of the four topics from pilot 1. Clear goal versions were straightforward, elaborate, and easy to understand. Unclear goal versions were short, ambiguous and not elaborated. For this pilot, 115 USbased participants were recruited through MTurk. Participants were randomly presented either the high or low goal clarity version of only one of the four topics. After reading the topic, they could write their opinions in a space provided. Then, they were asked to complete a goal clarity questionnaire for that topic, which was based on [32] (Cronbach $\alpha .93$ ). Since the conditions were presented in a random order, each condition had between 10-21 completed responses.

An independent samples t-test was conducted for the goal clarity scores for each of the four topics. Only for topic 1 (Should People Become Vegetarian), the mean goal clarity score of the high goal clarity condition $(M=22.90, S D=1.66, N=10)$ was significantly different from the low goal clarity condition $(M=17.00, S D=5.40, N=11), t(19)=$ $3.31, p=0.01$.

Thus, topic 1 (Should People Become Vegetarian) was found to have the most optimal combination of successful goal clarity manipulation and diversity of personal interest scores and was selected as the topic in the main study. The other topics were used as closed topics that illustrated the purpose of the online discuss in the high goal clarity conditions in the main study.

\subsection{Participants}

A total of 850 US residents were recruited through MTurk. Participants who did not complete all questionnaires were eliminated. Participants who failed 2 or more attention check questions (e.g. "please select agree if you are paying attention") were also eliminated. Finally, 631 participants (308 men, 320 women, 2 undisclosed, 1 transgender) remained. Each condition had between 152-166 completed responses.

\subsection{Measures}

Personal interest in topic was assessed using the same instrument as in pilot 1 (Cronbach $\alpha$.94). Perceived goal clarity was assessed using the same instrument as 
in pilot 2 (Cronbach $\alpha .93$ ). Motivation to contribute was assessed using eight items adapted from [45] (Cronbach $\alpha .90)$. Engagement in crowdsourcing was measured on three different dimensions:

Perception of active contribution assessed the willingness of the participants to contribute to the crowdsourcing activity. This scale used eight items adapted from the behavioral intention sub-scale, which is part of the TTM scale [78] (Cronbach $\alpha$.78).

Perception of cognitive engagement was assessed with seven items that were adapted from a cognitive and emotional engagement scale to measure work engagement [39] (Cronbach $\alpha .67$ ).

Perception of emotional engagement was assessed with seven different items that were also adapted from [39] (Cronbach $\alpha .81$ ).

\subsection{Measures}

Participants were randomly assigned to one of two conditions - high goal clarity or low goal clarity - the same topic (Should people become vegetarian?). Participants filled out an IRB consent page and read a task description, which varied by condition, i.e. high goal clarity condition explained the task purpose more clearly. The purported task purpose was to collect opinions on topics that are important to US citizens.

The experiment website was modeled on a mySidewalk template to mimic a real community crowdsourcing site. The high goal clarity website differed from the low goal clarity one in three ways. First, the goal was clearly explained. Second, participants had the opportunity to browse through the three closed challenges to understand the site layout and purpose. Third, the text entry boxes contained user guidance (e.g., 'enter title of your idea'). The physical appearance of the website (colors, set up, font, visuals etc.) was identical in both conditions to avoid con-founds. Both conditions had the same prefabricated ideas, comments, and likes to make the site appear 'live'.

Once the participants had provided their contributions, they filled out a series of surveys and were led to a debrief page. No time limit was imposed.

\section{Results}

To assess whether the manipulation was successful, a one-way analysis of variance was conducted between the high and low goal clarity groups. The results did not yield a significant difference $[F(2,629)=.12, p=$ .73]. Therefore, findings regarding goal clarity should be viewed with caution.

To ensure all structural equation modeling (SEM) analysis assumptions were met, the data were first screened for multicollinearity or redundancy of indicators. All relationships among indicators of interest were examined. The highest correlation was
.71, indicating that the assumption of nonmulticollinearity was met. Second, it was determined that all indicators met the normality assumption. Third, we confirmed that that the variance/covariance matrix was not ill scaled, meaning that the assumption of relative variances is met. Fourth, examining $z$ score frequencies from the grand mean we determined that there were no outliers for any indicators. Finally, since the observed variables for engagement were all selfreported measures, we used the techniques suggested by $[46,57,59,60]$ to test for the potential that the results were explained by common method variance. Our findings suggest that there was no common method bias in the data. A final confirmatory factor analysis confirmed that all items in the three engagement scales were significant on a single factor model. Therefore, we assumed that the items on the three scales indeed loaded on a single factor of engagement.

The goodness-of-fit indexes associated with the hypothesized model revealed an adequate fit $\left[\chi_{(18)}^{2}=\right.$ 41.91, $p=.00, C F I=.98, R M S E A=.05, S R M R=.02]$. Since the sample size is very large $(>600)$, the chisquare is significant. Since all modification indices were below 20 (as required for samples above 200) and the model showed an adequate fit, no further changes were made to the model.

To test the hypotheses, a path analysis model was tested using Mplus Version 7.3. The first hypothesis stated that crowdsourcing users who are more motivated to contribute would display greater engagement than users who are less motivated to contribute. The results indicated that motivation to contribute significantly predicted engagement $(B=$ $.145, S E=.024, \beta=.207, Z=6.04, p=0.00)$. This supports Hypothesis 1 .

The second hypothesis stated that crowdsourcing users who have a personal interest in the topic would be more motivated to contribute than users who are not interested in the topic. The results indicated that personal interest significantly predicted motivation to contribute $(B=.358, S E=.053, \beta=.461, Z=6.75, p$ $=0.00)$. This supports Hypothesis 2 .

The third hypothesis stated that motivation to contribute would partially mediate the relationship between personal interest in the topic and the level of engagement in the topic. The results indicated that motivation to contribute significantly predicted engagement $(B=.145, S E=.024, \beta=.207, Z=6.04, p$ $=0.00)$. Personal interest was also significantly related to motivation to contribute $(B=.358, S E=.053, \beta=$ $.461, Z=6.75, p=0.00)$. In addition, personal interest also significantly predicted engagement $(B=.318, S E$ $=.018, \beta=.583, Z=17.67, p=0.00)$. The indirect effect tested using bootstrapped standard errors was also significant $(B=.052, S E=.011, \beta=.095, Z=$ 
4.73, $p=0.00$ ). This supports Hypothesis 3's partial meditational model.

The fourth hypothesis stated that there would be an interaction between goal clarity and topic interest on motivation. Since the moderator variable is categorical, the STDY estimations were used (Muthen \& Muthen, 2012-2015). The results indicated that the interaction between personal interest and goal clarity was not significant $(B=-.041, S E=.058, \beta=-.008, Z=0.71, p$ $=0.48$ ). This does not support Hypothesis 4. However, one should be careful while interpreting these results as the unsuccessful manipulation may have resulted in the lack of significance.

\section{Discussion \& Conclusions}

Organizations that use crowdsourcing to generate ideas for community-based issues depend on community members being inspired to contribute without being offered any significant external rewards. Thus, the identification of factors that encourage active user performance and engagement are critical for community crowdsourcing to succeed. Consequently, this study investigated the relationship between engagement and some of its antecedents, namely, motivation, personal interest, and goal clarity. Summarizing, we found strong evidence that engagement was significantly related to motivation. We also found that engagement was significantly related to personal interest in the topic both directly and indirectly.

In addition to support for the direct relationships between personal interest, motivation, and engagement, we also found support for the mediating role of motivation in these relationships. This finding is a significant one since there is no study, to our knowledge, that investigates the relationships of these three components of a successful crowdsourcing initiative. However, researchers in online education reported similar findings in recent years. For example, Ding et al. [23] found that both the success of motivational strategies used by the educators and engagement of the students in the task was determined by the level of inherent personal interest of the students towards the task itself. Flowerday and Shell [25] found that both topical and situational interests were related to engagement directly and also indirectly through motivation.

The current study also sought to examine the role of goal clarity on user motivation. While no significant relationship was found, the results are called into question by the failure of the manipulation. It can be speculated that participants' prior experience with social media interactions may have intuitively guided their activities. As a result, the lack of clarity in the goal description itself may not have deterred the participants from understanding what was expected of them.

\subsection{Implications}

Our results provide initial guidance for organizations to create effective community crowdsourcing environments. Our study supports the idea that when the contributions are voluntary, it is important to ensure that there is some intrinsic benefit provided to the participants. Having a high level of personal interest in the topic enables the contributors to spend their time and energy evaluating and providing opinions on a forum that does not provide them with any immediate benefit. Since personal interest is a driver for motivation to contribute, organizations can hold focus groups or have crowdsourcing sessions to determine the issues that are most important to the communities. It would likely motivate citizens to contribute if the crowdsourcing site allowed them to determine the issues that they most want to talk about.

In addition, organizations can also work on framing their issues such that might be more interesting to the contributors. For example, instead of asking, "What are the alternative to using plastic grocery bags?" the question can be framed as "If grocery stores would start charging you to use plastic bags, what other alternatives would you consider?" Changing the context of the question may help frame the topic in a manner that makes it more interesting to the community thus attracting more contributions.

\subsection{Limitations and Future Directions}

A key limitation of this study is that it was a paid study. Even though we attempted to investigate engagement in community crowdsourcing, we used a market-based crowdsourcing approach to collect data. Since the study was based on the premise that participation in community crowdsourcing scenarios is voluntary, the fact that the participants were attracted to the study for monetary reasons may have distorted the results. Yet, the monetary rewards were small and the participants were given complete freedom to the extent they could participate (or not) without any impact on their rewards (they could stop engaging in the discussion on vegetarianism whenever they felt like and still receive full pay. Time spent on website ranged from 2 minutes to 25 minutes). Thus, it appears that this limitation was overcome to a large extent. Moreover, it is impossible to gain a representative population without some kind of initial extrinsic motivation. If we did not offer an extrinsic reward, then we would have had to count on people to be intrinsically motivated to participate in our study. Since we needed a diverse sample of individuals that were interested in the topic as well as people that were 
not interested in the topic, it would have been impossible to get a representative sample because only people with an interest in the topic would have signed up. In future studies, it would be useful to examine the validity of our model using a quasi-experimental design with actual community members. Using community members in an actual crowdsourcing website will ensure that the participation is indeed voluntary and will mitigate the potential confound of external rewards.

Another limitation is the fact that engagement was measured entirely through participants' perceptions. This may have led to the common method bias. Various measures were taken to ensure that the common method bias was not an issue. However, it should be borne in mind that these were merely diagnostic tests and there could be other sources of common method variance that have not been identified. Future studies and analyses could include more objective evidence such length of the ideas and comments or quality of the contribution.

Future research could investigate the impact of other factors of engagement that are discussed in the literature but were outside the scope of this study. For example, it can be examined if engagement and creativity are related in crowdsourcing ideation. Little is known about the antecedents of creativity in crowdsourcing settings. Future research could investigate if interventions can stimulate participant engagement and crowd creativity simultaneously or if improvements in one of these variables (engagement or creativity) come at the expense of the other. For instance, such interventions could focus on specific participant instructions in terms of format and wording or on the procedures that participants have to follow during which they can make contributions or are exposed to other participants' contributions.

Other examples of factors impacting engagement include but are not limited to personality, cultural background, and sensitivity of the discussion topic. Participants that score high on the neuroticism dimension of the five-factor model may respond differently to constructive criticism feedback than participants that score low on this dimension. Participants in a collectivist cultural environment may experience different motivation to sustain high engagement levels when they are identifiable in the crowd than participants in an individualistic environment. A participant's mood, for example agitated versus calm, may influence how contributions are formed, processed, and perceived resulting in different engagement levels. The sensitivity of the issue that is discussed in the crowdsourcing effort may also affect how contributions are formed and provided: When discussing a culturally or politically sensitive topic, participants may be overly cautious in formulating any additional contributions.

Finally, it would be interesting to assess whether this community crowdsourcing model for engagement fits other crowdsourcing scenarios. Different factors may drive engagement in market-based and rewardsbased crowdsourcing environments like idea competitions. In market-based crowdsourcing, participants receive a reward, typically in the form of monetary payment. It can be argued that their engagement during the completion of the task may still be influenced by their interest in the topic of the task, but it remains to be investigated how their level of interest interacts with their perceived value of the reward. In incentive-based crowdsourcing, participants are part of a competition for a monetary prize. Interest in the topic can still play a role in a participant's motivation to participate. It would be interesting to see how an individual's competitiveness and knowledge self-efficacy would moderate this relationship.

\section{References}

[1] Ajzen, I. (1991). The theory of planned behavior. Organization Behavior \& Human Dec. Processes, 50, 179-211.

[2] Anderson, J. R., \& Reder, L. M. (1979). An elaborative processing explanation of depth of processing. Levels of Processing in Human Memory, 385-404.

[3] Antonison, M. (2011). Evaluation of work engagement as a measure of psychological well being from work motivation. Dissertation Abstracts International, 72.

[4] Assor, A., Kaplan, H., \& Roth, G. (2002). Choice is good, but relevance is excellent: Autonomy-enhancing and suppressing teacher behaviours in predicting student's engagement in school work. British Journal of Educational Psychology, 72, 261-278.

[5] Bassuk, S., Glass, T., \& Berkman, L. (1999). Social disengagement and incident cognitive decline in community-dwelling elderly persons, Annals of Internal Medicine, 131, 165-173.

[6] Baum, J. R., Locke, E. A. \& Kirkpatrick, S. A. (2010). A longitudinal study of the relation of vision and vision communication to venture growth in entrepreneurial firms, Journal of Applied Psychology, 83, 43-54.

[7] Bayus, B. L. (2013). Crowdsourcing new product ideas over time: An analysis of the Dell IdeaStorm community. Management Science, 59, 226-244.

[8] Benton, S. L., Corkill, A. J., Sharp, J. M., Downey, R.G., \& Khramtsova, I. (1995). Knowledge, interest and narrative writing. Journal of Educational Psychology, 87, 66-79.

[9] Bobek, D., Zaff, J., Li, Y., \& Lerner, M. (2009). Cognitive, emotional, and behavioral components of civic action: Towards an integrated measure of civic engagement. Journal of Applied Developmental Psychology, 30, 615-627.

[10] Booth, C., Lowe, M., Tagge, N., \& Stone, S. M. (2014). Degrees of Impact: Analyzing the Effects of Progressive Librarian Course Collaborations on Student Performance. College \& Research Libraries.

[11] Brabham, D. (2009). Crowdsourcing the public participation process for planning projects. Planning Theory, 8, 242-262.

[12] Brabham, D. (2012). Motivations for participation in a crowdsourcing application to improve public engagement in 
transit planning. Journal of Applied Communication Research, 40, 307-328.

[13] Briggs, R. O., Adkins, M., Mittleman, D. D., Kruse, W. J., Miller, S., \& Nunamaker, J. F., Jr. (1999). A technology transition model. Journal of MIS, 15, 151-195.

[14] Chen, H. \& Nilan, M. (1999). Digital format of experience sampling method - transformation, implementation and assessment. Proceedings of AMCIS, 692-694.

[15] Connell, J., \& Wellborn, J. (1991). Competence, autonomy and relatedness: A motivational analysis of self-system processes. In Minnesota Symposium on Child Psychology (Vol. 22, pp. 43-77). Hillsdale, NJ: Erlbaum

[16] Craik, F. I. M. \& Lockhart, R. S. (1972). Levels of processing: A framework for memory research. Journal of Verbal Learning and Verbal Behavior, 11, 671-84.

[17] Davis, F. D., Bagozzi, R. P., \& Warshaw, P. R. (1989). User acceptance of computer technology: A comparison of two theoretical models. Management Science, 35, 982-1003.

[18] Davis, S. \& Wiedenbeck, S. (2001). The mediating effects of intrinsic motivation, ease of use and usefulness perceptions on performance in first-time and subsequent computer users, Interacting with Computers, 13, 549-580.

[19] Deci, E. L. (1992). The relation of interest to the motivation of behavior: A self-determination theory perspective. In K. A. Renninger, S. Hidi, \& A. Krapp (Eds.), The role of interest in learning and development (pp. 43-70). Hillsdale, NJ: Erlbaum.

[20] Deci, E. L., \& Ryan, R. M. (1985). The general causality orientations scale: Self-determination in personality. Journal of Research in Personality, 19, 109-134.

[21] Deci, E. L., \& Ryan, R. M. (1991). A motivational approach to self: Integration in personality. In R. Dienstbier (Ed.), Nebraska symposium on motivation: Vol. 38. Perspectives on motivation (pp. 237-288). Lincoln, NE: Univ. of NE Press.

[22] Deci, E., Koestner, R., \& Ryan, R. (1999). A meta-analytic review of experiments examining the effects of extrinsic rewards on intrinsic motivation. Psychological Bulletin, 125, 627-668.

[23] Ding, H., Sun, H., \& Chen, A. (2013). Impact of expectancy-value and situational interest motivation specificity on physical education outcomes. Journal of Teaching In Physical Education, 32(3), 253-269.

[24] Doan, A., Ramakrishnan, R., \& Halevy, A. (2011). Crowdsourcing Systems on the World-Wide Web. Communications of the ACM, 54, 86-96.

[25] Flowerday, T., \& Shell, D. F. (2015). Disentangling the effects of interest and choice on learning, engagement, and attitude. Learning And Individual Differences, 40, 134-140. doi:10.1016/j.lindif.2015.05.003

[26] Flowerday, T., Schraw, G., \& Stevens, J. (2004). The role of choice and interest in reader engagement. Journal of Experimental Education, 72, 93-114

[27] Fredericks, J. A., Blumenfeld, P. C., \& Paris, A. H. (2004). School engagement: Potential of the concept, state of the evidence. Review of Educational Research, 74, 59-109.

[28] Gao, H., Barbier, G., Goolsby, R., \& Zeng, D. (2011). Harnessing the crowdsourcing power of social media for disaster relief. Intelligent Systems, IEEE 26, 10-14.

[29] Gillet, N., Huart, I., Colombat, P. \& Fouquereau, E. (2013). Perceived organizational support, motivation, and engagement among police officers. Professional Psychology: Research and Practice, 44, 46-55.
[30] Goetz, E. T., \& Sadoski, M. (1995). Commentary: The perils of seduction: Distracting details or incomprehensible abstractions? Reading Research Quarterly, 500-511.

[31] Greene, B. A., \& Miller, R. B. (1996). Influences on course performance: Goals, perceived ability, and self-regulation. Contemporary Educational Psychology, 21, 181-192.

[32] Guo, Y. M., \& Poole, M. S. 2009. Antecedents of flow in online shopping: a test of alternative models. Information Systems Journal, 19, 369-390.

[33] Harter, J.K., Schmidt, F.L. \& Hayes, T.L. (2010). Businessunit-level relationship between employee satisfaction, employee engagement, and business outcomes: a meta-analysis. Journal of Applied Psychology, 87, 268-279

[34] Hidi, S. \& Harackiewicz, J. M. (2000). Motivating the academically unmotivated: A critical issue for the 21 st century. Review of Educational Research, 70, 151-179.

[35] Howe, J. (2008). Crowdsourcing: Why the power of crowd is driving the future of business. Crown Business.

[36] Hu, S., \& Kuh, G. (2002). Being (dis)engaged in educationally purposeful activities: The influences of student and institutional characteristics. Research in Higher Education, 43, 555-575.

[37] Jimerson, S., Campos, E., \& Greif, J. (2003). Toward an understanding of definitions and measures of school engagement and related terms. California School Psychologist, 8, $7-27$.

[38] Jose, P. E., \& Brewer, W. F. (1984). Development of story liking: Character identification, suspense, and outcome resolution. Developmental Psychology, 20, 911.

[39] Kahn, W. A. (1990). Psychological conditions of personal engagement and disengagement at work, Academy of Management Journal, 33, 692-724.

[40] Kardash, C. A. M., \& Amlund, J. (1991). Self-reported learning strategies and learning from expository text. Contemporary Educational Psychology, 16, 117-138.

[41] Kaufmann, N., Schulze, T., \& Veit, D. (2011). More than fun and money. Worker motivation in crowdsourcing-A study on Mechanical Turk. In AMCIS (Vol. 11, pp. 1-11).

[42] Kazai, G., Kamps, J., \& Milic-Frayling, N. (2012, November). The face of quality in crowdsourcing relevance labels: Demographics, personality and labeling accuracy. Proceedings of the 21st ACM International Conference on Information and Knowledge Management, Lahaina, HI.

[43] Kim, Y. H., Kim, D. J., \& Wachter K. (2013). A study of mobile user engagement (MoEN): Engagement motivations, perceived value, satisfaction, and continued engagement intention. Decision Support Systems, 56, 361-370

[44] Kruglanski, A. W. (1978). Endogenous attribution and intrinsic motivation. In M. R. Lepper \& D. Greene (Eds.), The hidden costs of reward: New perspectives on the psychology of human motivation (85-107). Lawrence Erlbaum.

[45] Lin, H.-F. (2006). Understanding behavioral intention to participate in virtual communities. Cyberpsychology \& Behavior: The Impact of the Internet. Multimedia and Virtual Reality on Behavior and Society, 9, 540-7.

[46] Lindell, M. K., \& Whitney. D. J., (2001). Accounting for common method variance in cross-sectional research designs. Journal of Applied Psychology, 86, 114-121.

[47] Liu, B., \& Tang, T. L. P. (2011). Does the love of money moderate the relationship between public service motivation and job satisfaction? Public Administration Review, 71, 718-727. 
[48] Locke, E. A., \& Latham, G. P. (2002). Building a practically useful theory of goal setting and task motivation: A 35-year odyssey. American Psychologist, 57, 705-717.

[49] Locke, E. A., Feren, D. B., McCaleb, V. M., Shaw, K. N., \& Denny, A. T. (1980). The relative effectiveness of four methods of motivating employee performance. In K. D. Duncan, M. M. Gruneberg, \& D. Wallis (Eds.), Changes in working life (pp. 363-388). London: Wiley.

[50] Lohman, M.C. (2006), Factors influencing teachers' engagement in informal learning activities, Journal of Workplace Learning, 18, 141-156.

[51] Macey, W. H., \& Schneider, B. (2008). The meaning of employee engagement. Industrial and Organizational Psychology: Perspectives on Science and Practice, 1, 3-30.

[52] Meece, J., Blumenfeld, P., \& Hoyle, R. (1988). Students' goal orientations and cognitive engagement in classroom activities. Journal of Educational Psychology, 80, 514-523

[53] Merriam-Webster.com. Retrieved July 15, 2014, from http://www.merriam-webster.com/dictionary/engaged

[54] Mollen, A., \& Wilson, H. (2010). Engagement, telepresence and interactivity in online consumer experience: Reconciling scholastic and managerial perspectives. Journal of business research, 63, 919-925.

[55] Nolen, S. (1988). Reasons for studying: Motivational orientations and study strategies. Cognition and Instruction, 5, 269-287

[56] Parker, L. E., \& Lepper, M. R. (1992). The effects of fantasy contexts on children's learning and motivation: Making learning more fun. Journal of Personality and Social Psychology, 62, 625-633.

[57] Pavlou, P., \& El Sawy, O. (2006). The case of new product development. Information Systems Research, 17, 198-227.

[58] Pinder, C. C. (2014). Work motivation in organizational behavior. Psychology Press.

[59] Podsakoff, P. M., \& Organ, D. W. (1986). Self-reports in organizational research: Problems and prospects. Journal of Management, 12, 69-82.

[60] Podsakoff, P. M., MacKenzie, S. B. Lee, J. -Y., \& Podsakoff, N. P. (2003). Common method biases in behavioral research: A critical review of the literature and recommended remedies. Journal of Applied Psychology, 88, 879-903.

[61] Puah, C., Bakar, A. Z. A., \& Ching, C. W. (2011, November). Strategies for community based crowdsourcing. In Research and Innovation in Information Systems (ICRIIS), 2011 International Conference on (pp. 1-4). IEEE.

[62] Renninger, K. A. (2000). Individual interest and its implications for understanding intrinsic motivation. In $\mathrm{C}$. Sansone \& J. M. Harackiewicz (Eds.), Intrinsic and extrinsic motivation: The search for optimal motivation and performance (pp. 375-407). New York: Academic.

[63] Renninger, K. (2003). Effort and interest. In J. Gutherie (Ed.), The encyclopedia of education (704-707). Macmillan.

[64] Rogstadius, J., Kostakos, V., Kittur, A., Smus, B., Laredo, J., \& Vukovic, M. (2011, May). An Assessment of Intrinsic and Extrinsic Motivation on Task Performance in Crowdsourcing Markets. In ICWSM Vol. 11.

[65] Ryan, R. M., \& Deci, E. L. (2000). Self-determination theory and the facilitation of intrinsic motivation, social development, and well-being. American Psychologist, 55, 68.

[66] Ryan, R. M., \& Stiller, J. (1991). The social contexts of internalization: Parent and teacher influences on autonomy, motivation and learning. In P. R. Pintrich \& M. L. Maehr (Eds.),
Advances in motivation and achievement: Vol. 7, Goals and selfregulatory processes (pp. 115-149). Greenwich, CT: JAI

[67] Sawyer, J. (1992). Goal and process clarity: Specification of multiple constructs of role ambiguity and a structural equation model of their antecedents and consequences. Journal of Applied Psychology, 77, 130-142.

[68] Schiefele, U. (1999). Interest and learning from text. Scientific Studies of Reading, 3, 257-279.

[69] Schiefele, U., Krapp, A. (1996). Topic interest and free recall of expository text. Learning \& Individual Differences, 8, 141-160. [70] Schraw, G. \& Lehman, S. (2001). Situational interest: A review of the literature and directions for future research. Educational Psychology Review, 13, 23-52.

[71] Simelane-Mnisi, S., \& Mji, A. (2014). Impact of feedback on assessment using clickers emerging technology to enhance learning. Edulearn14 Proceedings, 5344-5353.

[72] Skinner, E. A., \& Belmont, M. J. (1993). Motivation in the classroom: Reciprocal effects of teacher behavior and student engagement across the school year. Journal of Educational Psychology, 85, 571-581.

[73] Sonnentag, S., \& Volmer, J. (2010). What you do for your team comes back to you: A cross-level investigation of individual goal specification, team-goal clarity, and individual performance. Human Performance, 23, 116-130.

[74] Tardini, S., \& Cantoni, L. A. (2005). A semiotic approach to online communities: Belonging, Interest and identity in websites' and video games' communities. In Proceedings of the IADIS international conference (pp. 371-378).

[75] Tobias, S. (1994). Interest, prior knowledge, and learning. Review of Educational Research, 64, 37-54.

[76] Tobias, S. \& Everson, H.T. (1996). Assessing metacognitive knowledge monitoring. College Board Report No. 96-01. NY: The College Board

[77] Van Doorn, J., Lemon, K. N., Mittal, V., Nass, S., Pick, D., Pirner, P., \& Verhoef, P. C. (2010). Customer engagement behavior: Theoretical foundations and research directions. Journal of Service Research, 13, 253-266.

[78] Vreede, T. D., Vreede, G. D., Reiter-Palmon, R., \& Ashley, G. (2011). A Model of Technology Transition: Scale Development and Factor Analysis. Midwest Academy of Management 2011, 20-22.

[79] Wade, S. E. (1992). How interest affects learning from text. In K. A. Renninger, S. Hidi, \& A. Krapp (Eds.), The role of interest in learning and development (pp. 27-41). Hillsdale, NJ: Lawrence Erlbaum Associates

[80] Wade, S. E., Buxton, W. M., \& Kelly, M. (1999). Using think-alouds to examine reader-text interest. Reading Research Quarterly, 34, 194-216.

[81] Weinstein, C., \& Mayer, R. (1986). The teaching of learning strategies. Handbook of Research on Teaching, 3, 315-327.

[82] Willms, J. D. (2003). Literacy proficiency of youth: Evidence of converging socioeconomic gradients. International Journal of Educational Research, 39, 247-252.

[83] Zheng, H., Li, D., Hou, W. (2011). Task design, motivation, and participation in crowdsourcing contests. International Journal of Electronic Commerce, 15, 57-88.

[84] Schraw, G., Flowerday, T., \& Lehman, S. (2001). Increasing situational interest in the classroom. Educational Psychology Review, 13, 211-224 